\title{
PROPRIEDADES FÍSICAS DO SOLO EM FUNÇÃO DE DIFERENTES MANEJOS DE PASTAGEM
}

\author{
Bruno Eustáquio Cirilo Silva ${ }^{1}$, Eduardo Ferreira Medina ${ }^{2}$, Marlinda Rufina Jolomba ${ }^{3}$
}

\begin{abstract}
RESUMO - As propriedades físicas do solo são importantes indicadores de sua qualidade, visto que as plantas necessitam de solos bem estruturados para seu adequado desenvolvimento. Objetivou-se avaliar as propriedades físicas do solo sob diferentes sistemas. O experimento foi realizado em São Mateus-ES. Foram avaliadas as propriedades físicas do solo em dois sistemas: pastejo rotacionado e pastagem degradada em duas profundidades. Os dados oriundos dos diferentes sistemas foram submetidos à análise estatística pelo teste $\mathrm{T}$ de Student a $5 \%$ de probabilidade. Foram observados maiores valores absolutos de densidade na área de pastejo rotacionado, tanto na profundidade de $0-5 \mathrm{~cm}$ quanto na de 5-20 cm. A área com lotação rotacionada, apresentou maior resistência à penetração na camada de $0-5 \mathrm{~cm}$, com uma camada de compactação de 5,54 MPa, quando comparada à pastagem degradada na mesma profundidade com 1,21 Mpa, provavelmente devido às diferentes formas de uso e preparo do solo. O solo sob pastagem degradada apresentou maior quantidade de poros total nas duas profundidades analisadas. Como consequência, o teor de macroporos foi similarmente superior no solo com pastagem degradada com a tendência de maiores teores na camada de $5-20 \mathrm{~cm}$. O diâmetro médio geométrico variou entre 3,78 e 4,29 mm O solo com pastagem de sistema rotacionado apresentou média superior à área de pastagem degradada na profundidade de $5-20 \mathrm{~cm}$, indicando maior estabilidade de agregados nesses sistemas e evidenciando as vantagens do sistema em rotação. O teor de matéria orgânica variou pouco entre os tratamentos na camada superficial. Houve uma compensação nos atributos físicos que refletem a capacidade de retenção de água no solo, resultando em umidade na capacidade de campo semelhante para a lotação rotacionada e a pastagem degradada.
\end{abstract}

Palavras-chave: área degradada, capim-marandu, capim-mombaça, compactação, pisoteio animal.

\section{SOIL PHYSICAL PROPERTIES DUE TO DIFFERENT PASTURE MANAGEMENTS}

\begin{abstract}
The physical properties of the soil are important indicators of its quality, since the plants need well structured soils for their proper development. The objective was to evaluate the physical properties of the soil under different systems. The experiment was carried out in São Mateus-ES. The physical properties of the soil were evaluated in two systems: rotational grazing and degraded pasture in two depths. Data from the different systems were submitted to statistical analysis by Student's test at 5\% of probability. Higher absolute values of density were observed in the rotational grazing area, both in the depth of $0-5 \mathrm{~cm}$ and in the $5-20 \mathrm{~cm}$ depth. The area with rotational stocking showed higher resistance to penetration in the 0 $5 \mathrm{~cm}$ layer, with a compacting layer of $5.54 \mathrm{MPa}$, when compared to degraded pasture at the same depth with 1.21 MPa, probably due to the different forms of Use and preparation of the soil. The soil under degraded pasture had a higher amount of total pores in the two depths analyzed. As a consequence, the macropore content was similarly higher in the soil with degraded pasture with the trend of higher levels in the 5-20 $\mathrm{cm}$ layer. The average geometric diameter ranged from 3.78 to $4.29 \mathrm{~mm}$. The soil with rotated system pasture
\end{abstract}

\footnotetext{
${ }^{1}$ Departamento de Solos e Nutrição de Plantas, Universidade Federal de Viçosa, Viçosa-MG, Brasil, 36570-000. E-mail: brunomukuri@gmail.com

${ }^{2}$ Departamento de Solos e Nutrição de Plantas, Universidade Federal de Viçosa, Viçosa-MG, Brasil, 36570-000. E-mail: e.medinaufv@gmail.com

${ }^{3}$ Departamento de Zootecnia, Universidade Federal de Viçosa, Viçosa-MG, Brasil, 36570-000. E-mail: marjolomba29@gmail.com
} 


\begin{abstract}
presented a mean superior to the degraded pasture area in the depth of 5-20 cm, indicating greater stability of aggregates in these systems and showing the advantages of the system in rotation. The organic matter content varied little among the treatments in the superficial layer. There was a compensation in the physical attributes that reflect the water retention capacity in the soil, resulting in similar field capacity moisture for rotational stocking and degraded pasture.
\end{abstract}

Keywords: animal trampling, degraded pasture, marandu grass, mombaça grass, soil compaction.

\section{INTRODUÇÃO}

A maior parte das terras utilizadas na agropecuária no Brasil está ocupada com pastagens, cerca de 180 milhões de hectares, dos quais estima-se que mais da metade encontra-se em algum estágio de degradação (EMBRAPA, 2016). No estado do Espírito Santo existe cerca de 1,3 milhão de hectares de pastagens, com 15\% dessa área apresentando algum nível de degradação (GOVERNODOESTADODOESPÍRITO SANTO, 2015).

As pastagens constituem a base da alimentação na produção de ruminantes no país, porém a degradação dessas áreas, em várias regiões brasileiras, tem diminuído a produtividade das pastagens, comprometendo a sustentabilidade e a rentabilidade. À medida que a fertilidade diminui, há redução no potencial produtivo da forrageira, provocando uma queda na capacidade de suporte de animais (Oliveira et al., 2013).

Agramínea Panicum maximum (Jacq.) cv. Mombaça é uma forrageira utilizada para a formação de pastagens em regiões tropicais do Brasil devido à alta capacidade de produção de matéria seca, qualidade de forragem, facilidade de estabelecimento, aceitabilidade pelos animais e tolerância à seca (Müller et al., 2002; Mendonça et al., 2014), porém caracteriza-se por sua elevada exigência em fertilidade do solo (Freitas et al., 2007).

Dentre as espécies de Brachiaria, a mais utilizada é o capim-marandu (Brachiaria brizantha $\mathrm{cv}$. Marandu) conhecida popularmente por braquiarão. Essa gramínea, de acordo com Euclides et al. (2010), compõe 45\% da área pastagens cultivadas no Brasil e possui bom valor nutritivo e alta capacidade produtiva de matéria seca.

As propriedades físicas, químicas e biológicas dos solos são importantes indicadores, visto que as plantas necessitam de solos bem estruturados para seu adequado desenvolvimento, apresentando fundamental importância para a manutenção da qualidade e da produtividade do sistema (Marchão et al., 2007; Pignataro Netto et al., 2009; Bognola et al., 2010). De acordo com o uso e manejo, os solos se diferenciam em seu estado de agregação, textura, teor de água, matéria orgânica e possíveis tensões que o solo recebeu no passado (Llanillo et al., 2006).

O manejo animal extensivo, em geral, não obedece ao ciclo de desenvolvimento das forrageiras. Com o passar do tempo, as forrageiras não conseguem manter bom desenvolvimento, devido ao consumo da massa verde pelo animal, a falta de reposição dos nutrientes, a acidificação do solo, a perda da matéria orgânica e a compactação do solo, diminuindo a eficiência das pastagens. Com isso, pragas, plantas daninhas e, principalmente, a erosão hídrica, nos seus diversos estágios, passam a ocorrer na paisagem. Perdas do solo de aproximadamente $17 \mathrm{tha}^{-1} \mathrm{ano}^{-1}$ foram relatadas em cultivos de pastagens degradadas (Santos, 1997; Moreira et al., 2005).

A utilização de práticas conservacionistas de manejo do solo tem recebido grande ênfase, basicamente no que refere-se à manutenção e à melhoria das propriedades físicas, químicas e biológicas dos solos cultivados e suas implicações no rendimento das culturas (Spagnollo et al., 2002). A cobertura do solo, por exemplo, tem ação direta e efetiva na redução da erosão hídrica, pois promove a dissipação da energia cinética das gotas da chuva, diminuindo a desagregação das partículas de solo e o selamento superficial, aumentando a infiltração de água. Auxiliando assim, na diminuição do potencial erosivo da enxurrada (Cogo et al, 2003).

Considerando-se a importância econômica das pastagens para o Espírito Santo e para o Brasil, assim como a importância da conservação do solo, objetivouse avaliar as propriedades físicas do solo sob dois sistemas: pastagem rotacionada e degradada.

\section{MATERIAL E MÉTODOS}

O experimento foi realizado em uma fazenda comercial no município de São Mateus, localizada no 


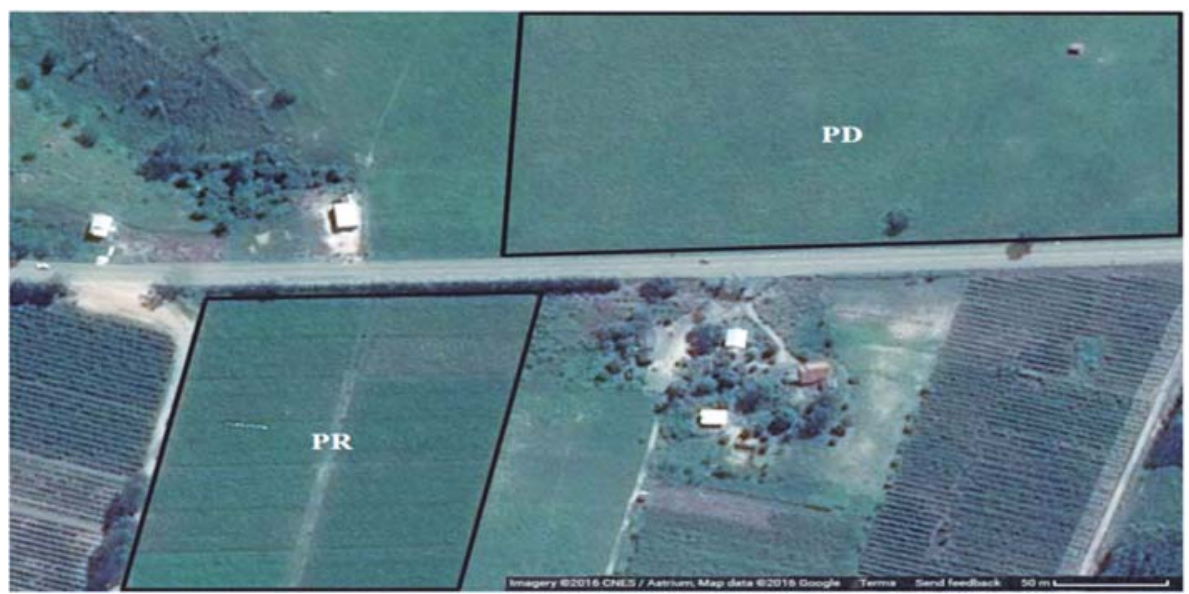

Figura 1 - Foto satélite da área do experimento. Retirada do Google maps em 28 de novembro de 2016.

$\mathrm{Km} 13$, cuja latitude é de $18^{\circ} 42^{\prime} \mathrm{S}$, longitude $39^{\circ} 57^{\prime}$ $\mathrm{O}$ e altitude média de 39 metros (Figura 1). O solo da região é classificado como argissolo amarelo distrófico coeso. O clima da região é quente e úmido (tipo Aw de Köppen), com estação seca no outono-inverno e estação chuvosa na primavera-verão (Alvares et al., 2013). Realizou-se a coleta do solo em setembro de 2016 e as análises físicas realizadas no laboratório de solos da Universidade Federal do Espírito Santo, UFES, campus São Mateus.

No experimento foi utilizado o delineamento em blocos casualizados. Foram amostrados solos sob pastagem submetidos a dois tipos de sistemas: lotação rotacionada, cultivado com capim-Mombaça (Panicum maximum) e pastagem degradada, cultivada com Brachiaria brizantha cv. Marandu sem nenhum manejo do solo. Em cada tipo de sistema foram retiradas oito amostras de solo, compreendidas em quatro pontos ao acaso e duas profundidades. A adubação foi realizada nas duas áreas de acordo com as necessidades nutricionais especificas de cada forrageiras. Em ambas as áreas, a pastagem foi irrigada nos momentos em que a precipitação fluvial foi insuficiente, sendo a lâmina aplicada calculada em função da evapotranspiração da cultura (ETc). As informações meteorológicas utilizadas para os cálculos da ETc foram fornecidas por uma estação climatológica automática instalada na área do experimento. A lotação animal foi a mesma para ambas as áreas. O solo analisado das duas áreas possui textura Argila-arenosa segundo triângulo textural (EMBRAPA, 2006). A análise textural e densidade de partícula estão apresentadas na Tabela 1.
Tabela 1 - Porcentagens de areia, silte e argila, e densidade de partículas de solos em área sob pastagem rotacionada e degradada em duas profundidades do solo em São Mateus - ES

\begin{tabular}{ccccc}
\hline Item & $\begin{array}{c}\text { Areia } \\
\left(\mathrm{g} \mathrm{kg}^{-1}\right)\end{array}$ & $\begin{array}{c}\text { Silte } \\
\left(\mathrm{g} \mathrm{kg}^{-1}\right)\end{array}$ & $\begin{array}{c}\text { Argila } \\
\left(\mathrm{g} \mathrm{kg}^{-1}\right)\end{array}$ & $\begin{array}{c}\text { Densidade de } \\
\text { partículas }\left(\mathrm{g} \mathrm{cm}^{-3}\right)\end{array}$ \\
\hline PR 0 - 5 cm & 514,32 & 64,00 & 421,68 & 2,45 \\
PR 5 -20 cm & 502,59 & 41,50 & 455,92 & 2,63 \\
PD 0 - 5 cm & 561,09 & 92,68 & 346,23 & 2,49 \\
PD 5 - 20 cm & 596,31 & 53,70 & 349,99 & 2,58 \\
\hline
\end{tabular}

PR: Pastagem rotacionada. PD: Pastagem degradada. Siglas seguidas de $0-5 \mathrm{~cm}$ e $5-20 \mathrm{~cm}$ indicam amostragens nas camadas entre $0-5$ e $5-20 \mathrm{~cm}$ de profundidade, respectivamente.

Coletaram-se amostras de solo deformadas, indeformadas e torrões nas camadas de $0-5$ e de 5 $20 \mathrm{~cm}$ de profundidade. As amostras deformadas foram coletadas com trado do tipo sonda e foram utilizadas para avaliação da argila dispersa em água (ADA) e para o teor de matéria orgânica. As amostras indeformadas foram coletadas utilizando um amostrador de Uhland, com anel volumétrico (tipo Kopecky) de $90 \mathrm{~cm}^{3}$ e foram utilizadas para avaliação da densidade do solo (DS), porosidade total (PT), macro e microporosidade, umidade na capacidade de campo, umidade atual do solo e resistência do solo à penetração (RP). Os torrões foram coletados com auxílio de enxadão e foram utilizados para determinação do diâmetro médio geométrico (DMG).

O teor de matéria orgânica foi obtido por oxidação via úmida com dicromato de potássio em meio sulfúrico (EMBRAPA, 2011). A argila dispersa em água e o grau 
de floculação foram determinados segundo metodologia da Embrapa (2011).

A densidade do solo foi obtida pela relação entre o peso da amostra seca a $105^{\circ} \mathrm{C}$ e o volume do anel. A porosidade total foi determinada por meio da relação entre densidade do solo e a densidade de partículas do solo. A microporosidade foi obtida por meio da quantidade de água retida nas amostras submetidas à tensão de $6 \mathrm{kPa}$. A macroporosidade foi calculada pela diferença entre a porosidade total e a microporosidade, sendo todos os procedimentos padronizados segundo a metodologia da Embrapa (2011).

A resistência do solo a penetração foi avaliada em condições de capacidade de campo. Utilizou-se um penetrógrafo de bancada com haste metálica e cone de três milímetros de diâmetro na sua extremidade. A haste penetrou o solo em uma velocidade de vinte milímetros por minuto. A resistência à penetração (RP, em MPa) foi calculada pela relação entre a força aplicado pelo cone sobre o solo ( $\mathrm{F}$, em $\mathrm{kgf}$ ) e a área do cone $\left(\mathrm{A}, \mathrm{em}^{2}\right)$, segundo a equação:

$$
R P=\frac{F 9,806648}{A 10^{6}}
$$

Para determinação do teor de água na capacidade de campo (CC), as amostras foram submetidas à tensão de $10 \mathrm{KPa}$. A umidade atual foi determinada pela relação entre o peso da amostra imediatamente após a coleta e o peso da amostra seca em estufa (EMBRAPA, 2011).

Para determinação do diâmetro médio geométrico, procedeu-se com a análise da estabilidade de agregados pelo método de peneiramento por via úmida, de acordo com metodologia preconizada pela Embrapa (2011), utilizando um aparelho de oscilação vertical (Yoder, 1936). O diâmetro geométrico foi calculado conforme metodologia de Gardner (1956).

Os dados oriundos dos diferentes sistemas foram submetidos à análise estatística pelo teste T de Student a $5 \%$ de probabilidade.

\section{RESULTADOS E DISCUSSÃO}

Analisando-se a Figura 2, pode-se observar maiores valores absolutos de densidade do solo tanto na camada de $0-5 \mathrm{~cm}$ quanto na de $5-20 \mathrm{~cm}$ na área de pastagem com sistema de lotação rotacionada do que na área de pastagem degradada. Corroborando com o encontrado

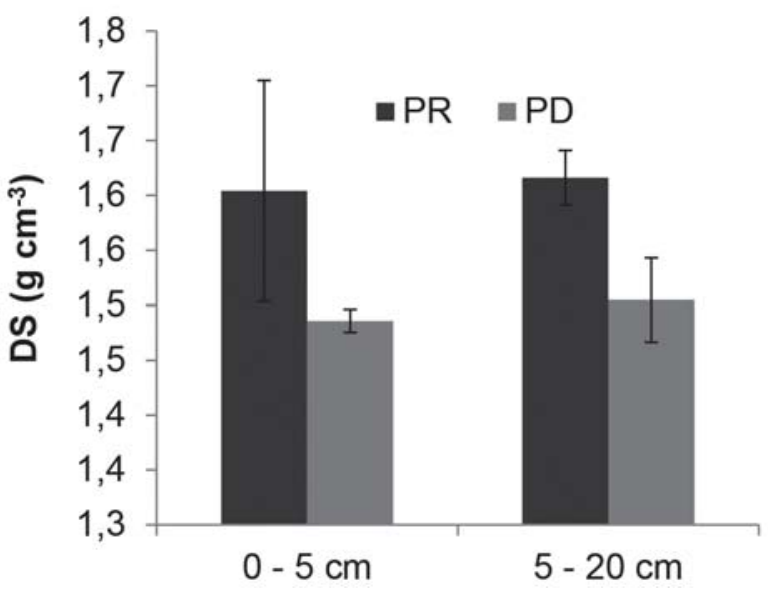

Figura 2 - Densidade do solo em área sob pastagem rotacionada e degradada em duas profundidades do solo em São Mateus - ES. PR: Pastagem rotacionada. PD: Pastagem degradada. Barras com as médias e erro padrão seguidas de asteriscos mostram diferença pelo teste $t$ de student a $5 \%$ de probabilidade.

por Bono et al. (2013), que observaram o aumento da densidade do solo nas camadas de 0-20 cm em áreas sob o cultivo de Brachiaria brizantha cultivar Marandu.

Segundo Miguel et al. (2009), em áreas de pastagens é comum a presença de camadas compactadas devido à pressão de pisoteio dos animais. Já em trabalho realizado por Silva et al. (2012), notou-se que em áreas cultivadas com milho, cana-de-açúcar e pastagem ocorreu um aumento nos valores desse atributo em decorrência ao pisoteio animal e ao uso excessivo de máquinas.

A densidade do solo por possuir estreita relação com outros atributos do solo é amplamente usada como indicador na maioria das pesquisas e converge para o fato de que, com o aumento da densidade do solo, ocorre diminuição da porosidade total, macroporosidade, condutividade hidráulica, absorção iônica, assim como o consequente aumento da microporosidade e da resistência mecânica à penetração de raízes (Lima et al., 2007).

Analisando a Figura 3, nota-se que a área com lotação rotacionada, apresentou maior resistência à penetração na camada de $0-5 \mathrm{~cm}$, com uma camada de compactação de 5,54 MPa, quando comparada à pastagem degradada na mesma profundidade com 1,21 MPa. 
Em trabalho realizado Vogel \& Fey (2016), os sistemas de pastagem apresentaram camadas mais compactadas nas profundidades até $20 \mathrm{~cm}$.

Segundo Bavoso et al. (2010) as alterações estruturais no solo devido às diferentes formas de uso e preparo do solo promovem alterações na resistência à penetração, corroborando este trabalho, em que o uso do solo juntamente com a carga animal, proporcionaram maior resistência à penetração.

Na Figura 4 são mostradas à porosidade total e a macroporosidade nos dois tipos de sistemas. A avaliacão

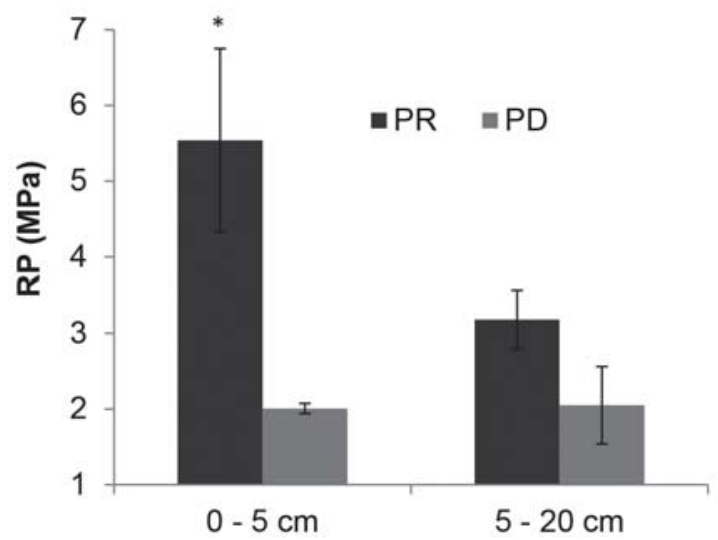

Figura 3 - Resistência à penetração em área sob pastagem rotacionada e degradada em duas profundidades do solo. PR: Pastagem rotacionada. PD: Pastagem degradada. Barras com as médias e erro padrão seguidas de asteriscos mostram diferença pelo teste $\mathrm{t}$ de student a $5 \%$ de probabilidade.

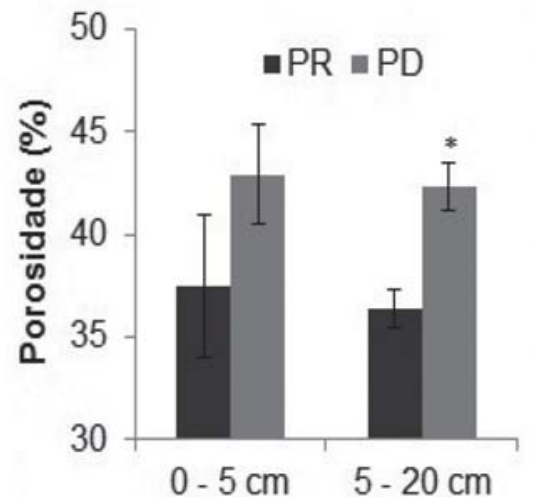

dos atributos fiìsicos mostrou que o solo sob pastagem degradada apresentou maior quantidade de poros total nas duas profundidades analisadas. Como consequência, o teor de macroporos foi similarmente superior no solo com pastagem degradada (Figura 4) com a tendência de maiores teores na camada de $5-20 \mathrm{~cm}$. Tendo em vista que esta área possui baixa produtividade se comparada ao pastejo rotacionado, os resultados indicam que esses atributos, assim como a RP e a Ds, foram sensiveis à ação do pisoteio na superfície, independentemente dos manejos de irrigação e de fertilidade do solo.

A microporosidade do solo foi superior na camada superficial de $0-5 \mathrm{~cm}$, com a tendência de maiores teores na área de pastagem rotacionada (Figura 5). Entretanto, os resultados obtidos na análise estatística pelo teste T de Student a 5\% de probabilidade nos dois tipos de sistemas, indica nenhuma influência do tipo de sistema neste atributo. Resultados similares foram obtidos por Lanzanova et al. (2007), onde os autores observaram a influência do pisoteio bovino na redução dos teores de macroporosidade e porosidade total, enquanto a porcentagem de microporos não sofreu alterações significativas pelos tipos de sistemas.

O diâmetro médio geométrico (DMG) variou entre 3,78 e 4,29 mm (Figura 6). O solo com pastagem de sistema rotacionado apresentou média superior à área de pastagem degradada na profundidade de $5-20 \mathrm{~cm}$, indicando maior estabilidade de agregados nesses sistemas e evidenciando as vantagens do sistema em rotação. O menor valor de DMG na área de pastagem degradada pode estar relacionado à maior exposição

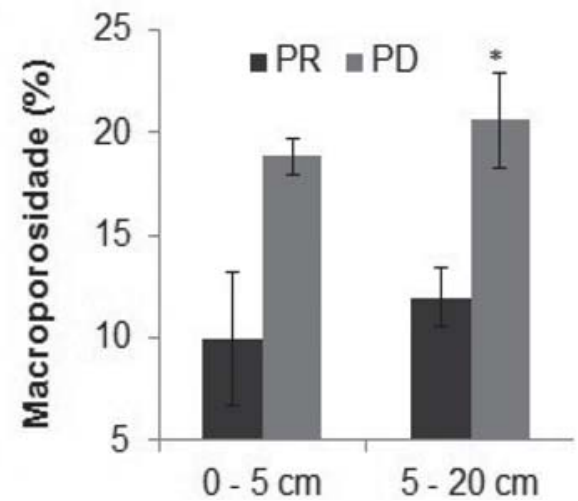

Figura 4 - Porosidade total (PT) e macroporosidade do solo em área sob pastagem rotacionada e degradada em duas profundidades do solo. PR: Pastagem rotacionada. PD: Pastagem degradada. Barras com as médias e erro padrão seguidas de asteriscos mostram diferença pelo teste $t$ de student a 5\% de probabilidade. 
à desagregação física causada devido ao rápido umedecimento pelo impacto da gota da chuva e pelo cisalhamento causado por implementos agrícolas (Tisdall \& Oades, 1982).

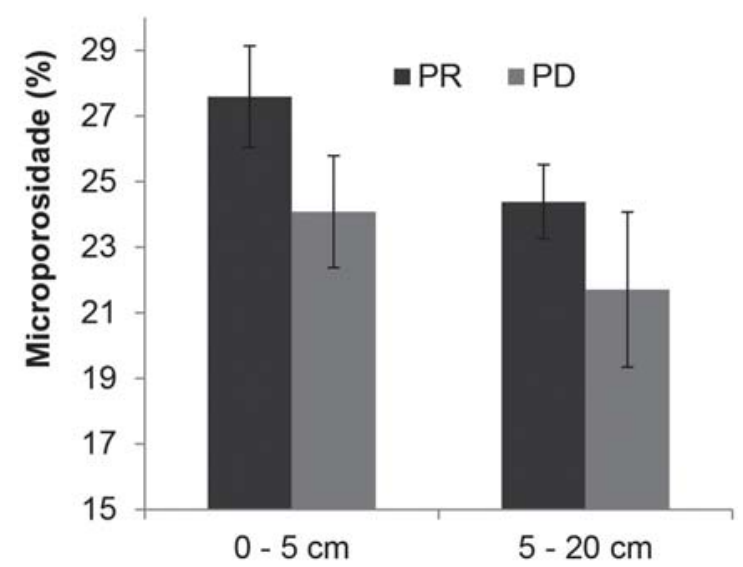

Figura 5 - Porcentagem de microporos do solo em área sob pastagem rotacionada e degradada em duas profundidades do solo. PR: Pastagem rotacionada. PD: Pastagem degradada. Barras com as médias e erro padrão seguidas de asteriscos mostram diferença pelo teste $\mathrm{t}$ de student a $5 \%$ de probabilidade.

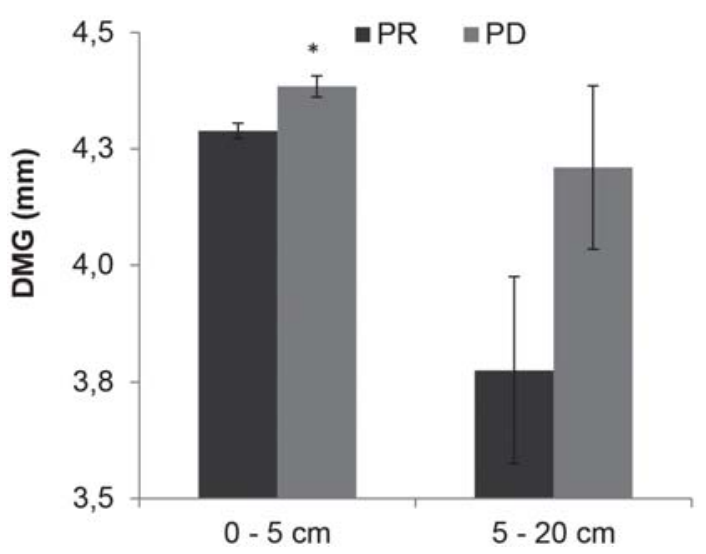

Figura 6 - Diâmetro médio geométrico (DMG) de agregados do solo em área sob pastagem rotacionada e degradada em duas profundidades do solo. PR: Pastagem rotacionada. PD: Pastagem degradada. Barras com as médias e erro padrão seguidas de asteriscos mostram diferença pelo teste $\mathrm{t}$ de student a $5 \%$ de probabilidade.
Nas camadas de 0-5 cm, contudo, a área degradada apresentou maior diâmetro médio geométrico que a área em sistema rotacional. Independente da área, as camadas de 0-5 cm apresentaram maior DMG que as camadas de 5-20 cm de profundidade (Figura 6), indicando menores riscos de erosão na camada superficial dos solos.

Segundo Silva et al. (2007), o diâmetro médio de agregados está relacionado com o teor de matéria orgânica, devido a atuação de compostos orgânicos na formação e estabilidade de agregados. Neste trabalho, o teor de matéria orgânica seguiu uma tendência similar ao DMG, como discutido a seguir.

O teor de matéria orgânica variou entre 1,13 e 2,83 dag $\mathrm{kg}^{-1}$ (Figura 7). O teor de matéria orgânica variou pouco entre as áreas estudadas na profundidade de 0-5 cm. Em relação a camada de $5-20 \mathrm{~cm}$, a área de pastejo rotacionado apresentou menor teor de matéria orgânica que a área de pastagem degradada.

A área com pastagem rotacionada apresentou teor de matéria orgânica na camada superficial 2,5 vezes superior à camada de $5-20 \mathrm{~cm}$. A redução da matéria orgânica em profundidade pode estar relacionada à maior deposição superficial de resíduos vegetais e animais, o que também foi constatado por Havlin (1990).

Ao analisar a Figura 8, verifica-se que a argila dispersa em água (ADA) foi maior na camada de 5-

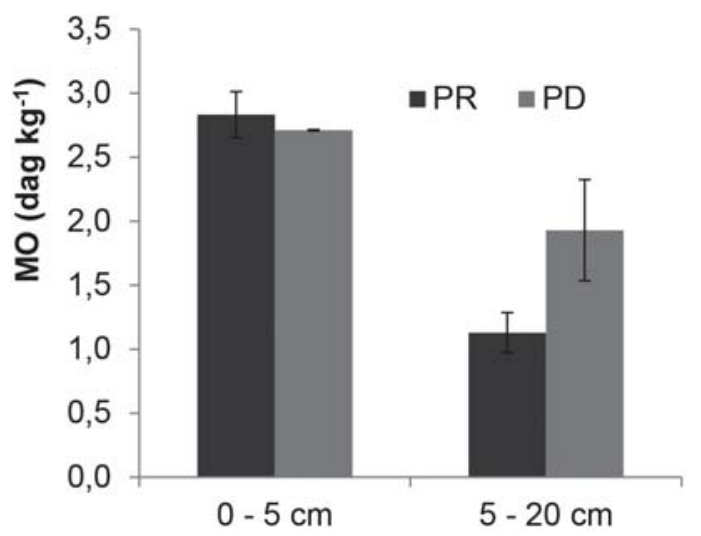

Figura 7 - Teor de matéria orgânica (MO) em área sob pastagem rotacionada e degradada em duas profundidades do solo. PR: Pastagem rotacionada. PD: Pastagem degradada. Barras com as médias e erro padrão seguidas de asteriscos mostram diferença pelo teste $\mathrm{t}$ de student a $5 \%$ de probabilidade. 


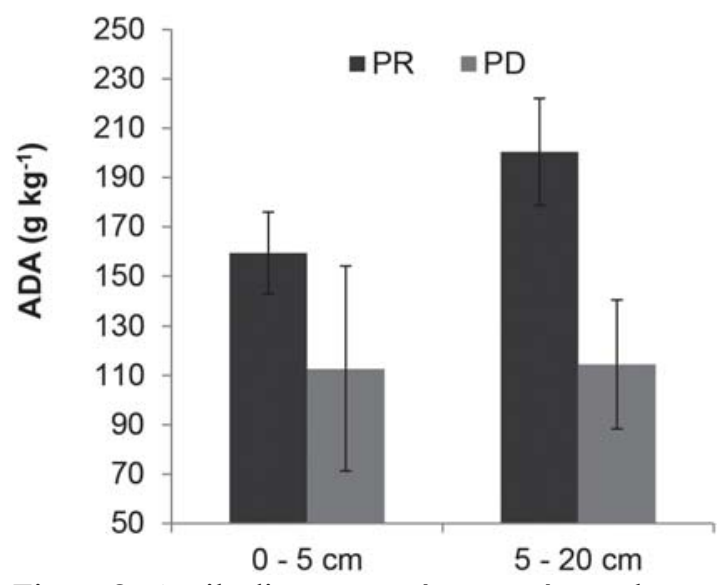

Figura 8 - Argila dispersa em água em área sob pastagem rotacionada e degradada em duas profundidades do solo. PR: Pastagem rotacionada. PD: Pastagem degradada. Barras com as médias e erro padrão seguidas de asteriscos mostram diferença pelo teste $\mathrm{t}$ de student a $5 \%$ de probabilidade.

$20 \mathrm{~cm}$, devido ao menor conteúdo da matéria orgânica, ocorrendo assim menor floculação. O aumento da ADA está diretamente relacionado com o decréscimo da infiltração de água nos latossolos brasileiros (Roth \& Pavan, 1991). Corroborando com o encontrado por Prado et al. (2001) observaram aumento da ADA com o aumento da profundidade.

Analisando a Figura 9 observa-se que o grau de floculação na camada de $0-5 \mathrm{~cm}$ foi maior que na camada de 5-20 $\mathrm{cm}<$ div, tanto na pastagem em sistema rotacionado quanto na pastagem degradada. A maior floculação na camada superficial estárelacionado ao também maior teor de matéria orgânica. Resultados semelhantes foram obtidos por Silva et al. (2000) visto que a matéria orgânica age como condicionador do solo mediante sua complexa e longa cadeia de carbono agregando partículas minerais.

A umidade aparente do solo no horário da coleta foi denominada Umidade atual (Figura 10). Para as duas profundidades analisadas, os valores de umidade atual foram superiores no pastejo rotacionado, valores atribuídos ao uso frequente de irrigações nesta área. Já as umidades na capacidade de campo (Figura 10), que refletem a capacidade de retenção de água no solo, foram superiores na camada mais superficial de 0-5

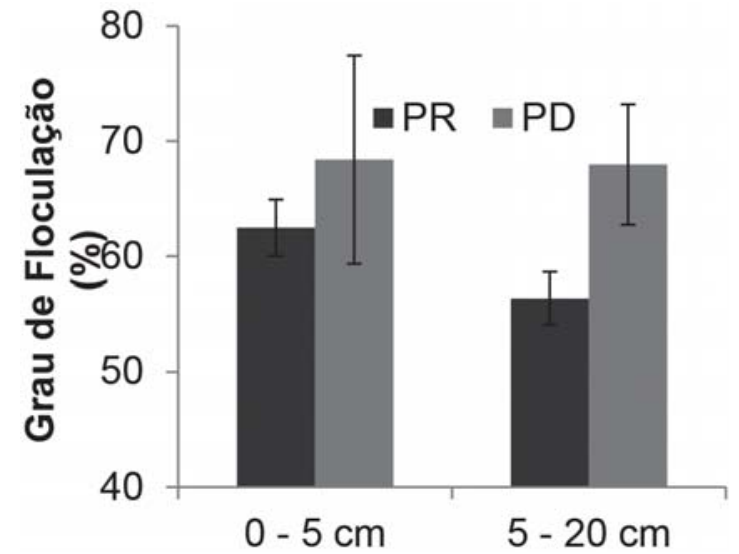

Figura 9 - Grau de floculação em área sob pastagem rotacionada e degradada em duas profundidades do solo. PR: Pastagem rotacionada. PD: Pastagem degradada. Barras com as médias e erro padrão seguidas de asteriscos mostram diferença pelo teste $\mathrm{t}$ de student a $5 \%$ de probabilidade.

$\mathrm{cm}$, com teores de 19,42 e 18,96 $\mathrm{g} \mathrm{g}^{-1}$ de água no pastejo rotacionado e na degradada, respectivamente. Provavelmente devido ao maior teor de matéria orgânica nesta camada (Figura 7).

Entre os tratamentos estudados, não foi observado diferença nos teores de umidade na capacidade de campo. A semelhança do comportamento dos dois solos quanto a este atributo, demonstra uma compensação nas propriedades que refletem a capacidade de retenção de água no solo, como a porosidade total, micro e macroporosidade, densidade do solo e matéria orgânica. Pois os mesmos atributos quando analisados separadamente, sofreram influência dos tipos de sistemas.

\section{CONCLUSÃO}

A densidade do solo, resistência do solo à penetração, porosidade total e macroporosidade foram sensíveis a ação do pisoteio animal na superfície. O diâmetro médio geométrico e o teor de matéria orgânica variou pouco entre os tratamentos na camada superficial. Houve uma compensação nos atributos físicos que refletem a capacidade de retenção de água no solo, resultando em umidade na capacidade de campo semelhante para o pastejo rotacionado e a pastagem 

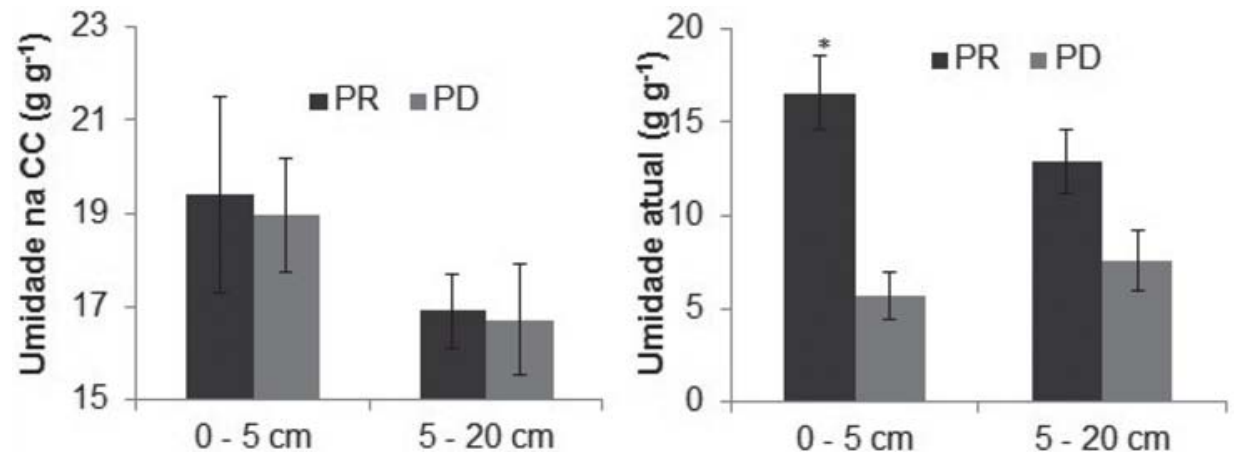

Figura 10 - Umidade atual e umidade na capacidade de campo (CC) do solo em área sob pastagem rotacionada e degradada em duas profundidades do solo. PR: Pastagem rotacionada. PD: Pastagem degradada.

degradada.

\section{LITERATURA CITADA}

ALVARES, C.A.; STAPE, J.L.; SENTELHAS, P.C. et al. Koppen's climate classification map for Brazil. Meteorologische Zeitschrift, v.22, p.711-728, 2013.

BAVOSO, M.A.; GIAROLA, N.F.B.; TORMENA, C.A. et al. Preparo do solo em áreas de produção de grãos, Silagem e pastejo: efeito na resistência tênsil e friabilidade de agregados. Revista Brasileira de Ciência do Solo, Viçosa, v.34, p.227-234, 2010.

BOGNOLA, I.A.; DEDECEK, R.A.; LAVORANTI, O.J. et al. Influência de propriedades físico hídricas do solo no crescimento de Pinus taeda. Pesquisa Florestal Brasileira, Colombo, v.30, n.61, p.37-49, 2010.

BONO, J.A.M.; MACEDO, M.C.M.; TORMENA, C.A. Qualidade física do solo em um latossolo vermelho da região sudoeste dos cerrados sob diferentes sistemas de uso e manejo. Revista Brasileira de Ciência do Solo, v.37, p.743-753, 2013.

COGO, N.P.; LEVIEN, R.; SCHWARZ, R.A. Perdas de solo e água por erosão hídrica influenciadas por métodos de preparo, classes de declive e níveis de fertilidade do solo. Revista

Brasileira de Ciência do Solo, v.27, n.4, p.743-753, 2003.

EMBRAPA - EMPRESA BRASILEIRA DE
PESQUISA AGROPECUÁRIA. Sistema brasileiro de classificação de solos. 2 . ed. Rio de Janeiro: CNPS, 2006. 306p.

EMPRAPA - EMPRESA BRASILEIRA DE PESQUISA A GROPECUÁRIA. Manual de métodos de análises de solo. 2.ed. Rio de Janeiro: Embrapa Solos, 2011.230p.

EMBRAPA - EMPRESA BRASILEIRA DE PESQUiSA AGROPECUÁRIA. Pecuária mais eficiente pouparia atmosfera de 30 milhões de toneladas de $\mathrm{CO}_{2}$ por ano. Disponível em: <http://www.embrapa.br/ busca-de-noticias/-/noticia/7545578/pecuariamais-eficiente-pouparia-atmosfera-de-30-milhoesde-toneladas-de-co2-por-ano>. Acesso em: 28 de nov. 2016.

EUCLIDES, V.P.B.; MACEDO, M.C.M; VALLE, C.B. et al. Valor nutritivo da forragem e produção animal em pastagens de Brachiaria brizantha. Pesquisa Agropecuária Brasileira, v.44, n.1, jan. 2009.

FREITAS, K.R.; ROSA, B.; RUGGIERO, J.A. et al. Avaliação da composição químicobromatológica do capim Mombaça (Panicum maximum) submetidos a diferentes doses de nitrogênio. Bioscience Journal, v.23, n.3, p.1-10, Jul/set, 2007.

GARDNER, W.R. Representation of soil aggregate-size distribution by a logarithmicnormal distribution. Soil Science Society of America Journal, v.20, p.151-153, 1956. 
GOVERNO DO ESTADO DO ESPÍRITO SANTO.

Orientação e manejo adequado na recuperação de área degradada. 2015.

HAVLIN, J.L. Crop rotation and tillage effects on soil organic carbon and nitrogen. Soil Science Society of America Journal, v.54, n.2, p.448-452, 1990.

LANZANOVA, M.E.; NICOLOSO, R.S.; LOVATO, T. et al. Atributos físicos do solo em sistemas de integração lavoura-pecuáriasob plantio direto.

Revista Brasileira de Ciência do Solo, v.31, n.5, p.1131-1140, 2007.

LIMA, C.G.R.; CARVALHO, M.P.; MELLO, L.M.M. et al. Correlação linear e espacial entre a produtividade de forragem, a porosidade total e a densidade do solo de Pereira Barreto (SP).

Revista Brasileira de Ciência do Solo, v.31, n.5, p.1233-1244, 2007.

LLANILLO, R.F.; RICHART, A.; FILHO, J.T. et al. Evolução de propriedades físicas do solo em função dos sistemas de manejo em culturas anuais. Semina: Ciências Agrárias, v.27, n.2, p.205-220, 2006.

MARCHÃO, R.L.; BALBINO, L.C.; SILVA, E.M. et al. Qualidade de um Latossolo Vermelho sob sistemas de integração lavoura-pecuária no Cerrado. Pesquisa Agropecuária Brasileira, v.42, p.873-882, 2007.

MENDONÇA, V.Z.; MELLO, L.M.M.; PEREIRA, F.C.B.L. et al. Corn production for silage intercropped with forage in the farming-cattle breeding integration. Engenharia agrícola, v.34, n.4, p.738-745, 2014.

MIGUEL, F.R.M.; VIEIRA, S.R.; GREGO, C.R. Variabilidade espacial da infiltração de água em solo sob pastagem em função da intensidade de pisoteio. Pesquisa Agropecuária Brasileira, v.44, p.1513-1519, 2009.

MÜLLER, M.S.; FANCELLI, A.L.; DOURADONETO, D. et al. Produtividade do Panicum maximum cv. Mombaça irrigado, sob pastejo rotacionado. Scientia Agrícola, v.9, n.3, p.427-433, 2002.
OLIVEIRA, T.C.; PEREIRA, D.N.; BRITO, T.E. et al. Diagnóstico e recuperação de áreas de pastagens degradadas. Revista

Agrogeoambiental, Edição Especial n.1, p.4953, 2013.

PIGNATARO NETTO, I.T.; KATO, E; GOEDERT, W.J. Atributos físicos e químicos de um latossolo Vermelho-amarelo sob pastagens com diferentes históricos de uso. Revista Brasileira de Ciência do Solo, v.3, p.1441-1448, 2009.

PRADO, R. De M.; CENTURION, J.F. Alterações na cor e no grau de floculação de um latossolo vermelho-escuro sob cultivo contínuo de cana-deaçúcar. Pesquisa Agropecuária

Brasileira, n.36, v.1, p.197-203, 2001.

ROTH, C.H.; PAVAN, M.A. Effects of lime and gypsum on clay dispersion and infiltration in samples of a Brazilian Oxisol. Geoderma, v.48, p.351-361, 1991.

SANTOS, M.N. Influência de diferentes sistemas de manejo nos teores de carbono orgânico e nutrientes e no tamanho e distribuição de poros em um latossolo vermelho escuro argiloso na região dos cerrados. 1997. Dissertação. (Mestrado em Agronomia) - Universidade de Brasília, Brasília.

SILVA, P.C.; COSTA, R.A.; BARBOSA, K.F. et al.

Propriedades físicas indicadoras da qualidade do solo sob diferentes culturas e sistemas de manejo. IV Jornada Acadêmica, Santa Helena de Goiás, 2012.

SILVA, V.R.; REINERT, D.J.; REICHERT, J.M. Susceptibilidade à compactação de um Latossolo Vermelho Escuro e de um Podzólico Vermelho Amarelo. Revista Brasileira de Ciência do Solo, v.24, n.2, p.239-249, 2000.

SILVA, A.J.N.; RIBEIRO, M.R.; CARVALHO, F.G. et al. Impact of sugarcane cultivation on soil carbon fractions, consistence limits and aggregate stability of a yellow latossol in Northeast Brazil. Soil and Tillage Research, v.95, n.4, p.420424, 2007.

SPAGNOLLO, E.; BAYER, C.; WILDNER, L.P. et al. Leguminosas estivais intercalares como fonte de nitrogênio para o milho, no sul do Brasil. 
Revista Brasileira de Ciência do Solo, Soil Science, v.33, p.141-163, 1982. v.26, n.2, p.417-423, 2002.

TISDALL, J.M.; OADES, J.M. Organic matter and water-stable aggregates in soil. Journal of

VOGEL, G.F.; FEY, R. Resistência mecânica à penetração em diferentes sistemas de uso do solo. Revista de Agricultura Neotropical, v.3, n.1, p.21-26, 2016.

YODER, R.E. A direct method of aggregate analysis of soils and a study of the physical nature of erosion. American Society of Recebido para publicação em 2/5/2017 e aprovado em 4/9/grompomy Journal, v.28, p.337-351, 1936, 